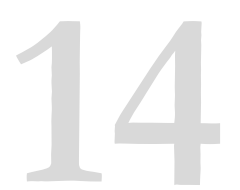

\title{
Climate-induced migration in Lotofaga village in Samoa
}

\author{
Ximena Flores-Palacios
}

\begin{abstract}
Climate-induced migration has received increasing attention in both research and policy. However, the voices of people affected by climate change are in most cases neglected. People's voices and perspectives are important, not only because affected people should have a right to be listened to and to participate in decisionmaking, but also because they have considerable knowledge (traditional and other), which must be taken into account and which can provide valuable input to future initiatives.

This chapter explores people's experiences and understandings of climate change, including whether and how climate-related factors have influenced internal and international population movements in Lotofaga, a village located on the south coast of Upolu Island in Samoa. The main finding of the study is that even though climate change is affecting people's lives, families are demonstrating great strength and resilience. They are using a mix of traditional and Western modern technical knowledge, drawing on their family and village social support systems, utilising their customary land tenure entitlements, and using population movements to enhance their adaptive capacity.
\end{abstract}

Cite this article: Flores-Palacios, X. (2019): Climate-induced migration in Lotofaga village in Samoa. In: Klöck, C. \& Fink, M. (eds.): Dealing with climate change on small islands: Towards effective and sustainable adaptation? (pp. 313-337). Göttingen: Göttingen University Press. https://doi.org/10.17875/gup2019-1222 


\section{Introduction}

Environmental factors have always had an impact on migration flows; throughout history, people have left places with harsh or deteriorating conditions. However, the accelerated and combined impacts of climate change have become so serious that the scale of movement is increasing and has unprecedented impacts on people's lives and livelihoods (International Organization for Migration, 2016).

Over the past decades, human mobility associated with climate change and extreme weather events has been gaining increasing attention in academic and policy arenas. However, this relatively new topic presents challenges because the reasons people migrate are multi-faceted and so disentangling climate from other migration drivers is difficult.

Moreover, contemporary research on climate change has tended to give prominence to physical phenomena and technological interventions, and less attention to economic, social, and cultural implications. For instance, there is a paucity of literature on people's experiences of the effects of climate change on their lives, livelihoods, social systems, and decision-making processes that include population movements.

The knowledge and experience people bring to the debate is hardly considered either. Moreover, in the literature, Pacific peoples are represented as vulnerable, with limited recognition being given to their resilience in the face of external pressures and forces (McNamara \& Gibson, 2009; Paton \& Fairbairn-Dunlop, 2010). I therefore saw the need to explore Pacific people's explaining their experiences to add meaning to the many technical reports and political discourses on environmental migration.

Research on environmental migration that takes people's experiences into account is necessary to be able to design better policies and practices in order to address internal and international movements. Such research can also highlight lessons that need to be learned from existing government responses and local initiatives to reduce people's vulnerability, as well as help increase understanding of how human mobility might be used as part of adaptation strategies.

The aim of the research discussed in this chapter was to explore and understand how climate-related factors influence people's mobility patterns in Lotofaga, a village located on the south coast of Upolu Island in Samoa.

The research questions were:

- How do people perceive and manage the impacts of climate change?

- How have climate change impacts played a role in people's decisions to move internally and internationally?

Another aim was to inform policy design and practices related to climate-induced mobility, through recognising the unique natural and cultural assets of Samoan communities, their close ties to their customary land tenure systems, the role of 
extended families as a mechanism for resilience, and the decision-making processes of local communities.

The chapter is organised into five sections. Following this introduction, Section 2 reviews the literature. Section 3 describes the methodological approach, which is underpinned by a Samoan perspective and a Western one. Section 4 presents the village study findings. Section 5 concludes by highlighting the necessity of working in collaboration with affected communities in order to ensure effective policy decisions.

\section{$2 \quad$ Literature review}

\subsection{Migration associated with climate change}

Climate-induced migration is a cross-cutting development issue that requires an interdisciplinary understanding. My standpoint for this study is that advancing discussions and developing a comprehensive theoretical framework and policy response requires reviewing these phenomena from a range of different knowledge systems.

Over the last decades, there has been a growing recognition that environmental and climate changes are important drivers of migration. However, understanding the linkages between climate change and population movements presents many challenges (Campbell, 2010). While environmental and climate change can exacerbate population movements, and while weather events very likely contribute to an increased level of mobility and changing migration patterns, disentangling climate change from other migration drivers is not easy. Usually, a complex combination of causes determines whether or not people move. Therefore, given the multiple causes of migration, it is not straightforward to draw a clear line between voluntary and forced movements (Hugo, 1996; Laczko \& Piguet, 2014). Stephenson, Newman, and Mayhew (2010, p. 153) state that the reasons for which people migrate or seek refuge are multi-faceted, making it hard to forecast how climate change will affect the future of migration. However, climate change seems likely to become a major force for future population movements, probably mostly through internal displacement but also to some extent through international migration, particularly for small island states.

Dun and Gemenne (2008, p. 10) write that

aside from clear cases where sudden-onset environmental changes such as those resulting from tsunamis, earthquakes or floods lead to forced displacement, the problem is that environmental migration frequently presents itself where there is a slow-onset environmental change or degradation processes such as desertification or increasing sea level.

Views are that the complexity of current migration patterns and the challenges of isolating environmental factors from other migration drivers have inhibited the 
development of robust theoretical frameworks (IOM, 2016). Burson (2010, p. v) argues that "while it might be tempting to characterize climate change [in the context of human mobility] as a new and self-standing phenomenon, it is more correct that it be seen as a set of interrelated factors affecting human security and development." Therefore, migration is better characterised as having multiple causal factors, and climate change as an additional factor driving migration in an array of existing drivers.

\subsection{Research on environmental migration in the Pacific Island countries and territories (PICTs)}

Over the last decades there has been a growing interest in the relationship between climate change and population movements in the Pacific. The perception that large numbers of people may be forced to migrate because of the effects of climate change and sudden-onset weather events has fuelled interest in this topic, particularly the study of atoll countries (Bedford \& Hugo, 2012; Connell, 2011; Hugo, 1996, 2008; see also Hermann \& Kempf, this volume). Researchers from different disciplines have been working on conceptual and empirical studies of environmental migration, and also on policy frameworks (UNU-EHS \& UNESCAP, 2015). Empirical research has found that environmental factors can play a role in migration (Barnett \& O'Neill, 2012). In some cases, there might be a direct correlation, particularly between a sudden-onset event and displacement, while the relationship might be more indirect in cases of slow-onset events. In terms of migration as adaptation to climate change, the scholarly literature has examined a number of climatic stressors and locations, making it difficult to explain whether migration is a form of adaptation or an indicator of the limits to adaptation (Barnett \& O'Neill, 2010). Although there have been remarkable efforts to address the topic of climate-induced migration in the Pacific region, theoretical frameworks and methodologies used across studies differ from one another, and they have not been linked to policy interventions. In most cases, theoretical and methodological underpinnings to climate-induced migration have been developed ad hoc to meet specific research needs. Additionally, in the Pacific, there is no reliable data on population movements, and limited information on the projected effects of climate change regarding how much and whether such effects will reduce land, livelihood, and habitat security to the point of inducing or forcing mobility (Campbell \& Bedford, 2014).

Research on environmental migration in PICTs presents additional gaps. Climate change discussions have largely been the domain of scientists, academics, politicians, and development practitioners. The voices of the people directly exposed to climate change have, in most cases, been neglected (Paton \& FairbairnDunlop, 2010). There is an urgent need to emphasise the human face of climate change and population movements. 
There is also a need to consider the largely unexplored application of indigenous theoretical and methodological frameworks in the area of environmental migration. Many scholars in various parts of the world have questioned the uncontextualised application of approaches and methodological frameworks originated in Western countries to different regions of the world (Battiste, 2000; Chilisa, 2012; Smith, 1999). Pacific researchers are calling for more authentic and grounded research practices that promote the capacity of Pacific people not only to theorise their own lives, but also to reconnect with past and future generations (Anae, Coxon, Mara, Wendt-Samu, \& Finau, 2001; Gegeo \& Watson-Gegeo, 2001; NaboboBaba, 2008; Thaman, 2007).

While Western research and practice dominate climate change debates, traditional knowledge, values, and beliefs are essential elements of navigating the way forward for affected communities. Therefore, this study is underpinned by both a Samoan perspective and a Western one.

\section{Methodological approach}

\subsection{Country selection}

Climate change is a challenge for all PICTs. However, I saw the importance of carrying out an in-depth study in a single country. I decided to make Samoa my study focus because while more research has been conducted in highly vulnerable atoll territories, there has been little empirical research on the influences of climate change on middle-sized Pacific nations such as Samoa. The Samoan context offered the opportunity to isolate the research topic from other external factors. The country presents political stability, steady economic growth, and good social development (Government of Samoa, 2014).

Samoa has a total land area of 2,830 km², and the estimated population in 2016 was $195,979.20 \%$ of the population live in Apia, the capital, and $80 \%$ live in rural areas, in small villages dotted mainly around the coastlines of the larger islands of Upolu and Savaili. Between 70 and $80 \%$ of the population live beside or within a kilometre of the coast, and approximately $70 \%$ of the infrastructure is located in low-lying coastal areas (Samoa Bureau of Statistics, 2016).

\subsection{Lotofaga - Particularities of the village case study}

While climate change affects all the coastal villages in Samoa, it was necessary to explore and understand patterns and dynamics of population movements (internal and international) associated with climate change in one selected village. Two criteria were established to select the village study: (i) The location should be a rural village with lowland coastal areas and sites ranked highly vulnerable to extreme weather events and adverse impacts of climate change; and (ii) it should show evi- 
dence of internal movements and migration to New Zealand associated in some way with climate change. After analysing various options, I selected the village of Lotofaga on the south coast of Upolu (see Figure 1).



Figure 1: Geographical location of Lotofaga in Samoa. Map: Patrick D. Nunn.

\section{Socio-economic aspects}

The village of Lotofaga has a population of almost 1,000, which has been decreasing because of significant levels of out-migration (Samoa Bureau of Statistics, 2016). Three patterns of mobility have been identified in Lotofaga, namely movements inland within the village, migration to Apia, the capital, and migration abroad (mainly to New Zealand). Furthermore, displacement has occurred after sudden-onset weather events.

As in many rural areas, people are engaged in semi-subsistence activities, a combination of farming, keeping livestock, fishing, and using other natural resources. With respect to village livelihoods, all families have plantations and vegetable gardens. Almost all households raise poultry and pigs, and a small percentage own cattle (Samoa Bureau of Statistics, 2011). Traditional coping mechanisms in times of hardship include customary safety nets, where remittances undoubtedly play a key role, and migration to diversify family income.

Life in the village is largely guided by fa'a Samoa, the Samoan way of life, that has remained strong, despite long exposure to Western influences. Fa'a Samoa sets 
the cultural, social, and economic guiding principles for life within Samoan society. It provides the ideological platform of relationships between God, family systems, and natural resources endowment 'for the use of those to come'. Thus, fa' a Samoa revolves around the 'aiga, (extended family), nu'u (village), and lotu (church) (Fairbairn-Dunlop, 1991; Lay, Tamua, Murrow, \& Meleisea, 2000; Meleisea, 1987; Va'a, 2007).

\section{The importance of land}

Customary land is fundamental to Samoan society and its value cannot be assessed only in economic terms because of its symbolic and cultural significance. Land and sea are the major resources in every Samoan village as the source of food security and livelihoods. Less well documented is that the family land represents identity, belonging, family history, culture, community, family prestige, and pride even for migrant communities where names and titles signify location and identity (Fairbairn-Dunlop, 2000). All family members have entitlement to family lands; however, customary land cannot be sold, but is passed from generation to generation.

Land in Lotofaga is held in accordance with Samoan custom and usage. The customary land tenure is held under the stewardship of the family matai (chief), who has the duty of ensuring that family members have equitable access to land so as to meet their basic needs. As regards sea resources, Samoa has a system of property rights on reef and lagoon areas. This system is characterised by legal ownership by the state, combined with customary ownership of fishing rights by community village groups (Fairbairn-Dunlop, 1991).

The relationships that people have with their land, sea, and the environment, and the spirituality that binds them together, are the basis for the wellbeing and resilience of people in Lotofaga and their culture. This holistic approach to life and the complex yet harmonious relationships have sustained people's way of life over generations.

In earlier times, Lotofaga followed a common configuration and land use pattern of a Samoan coastal village, with its main coastline settlement around the malae (meeting place) with a belt of inland coconut and other plantations. The village malae for the fono o matai (chief council) is still at the coastal site. However, over the last three decades much of the village settlement has extended into the hills largely as a result of the introduction of cash cropping, supported in turn by government economic development schemes, which have promoted projects to build roads inland to the plantations, and, more recently, responses to climate change and sudden-onset weather events. 


\section{Vulnerability to climate change and extreme events}

Lotofaga, like many rural villages in Samoa, is particularly vulnerable to the effects of climate change and extreme weather events because of its coastal location and families' reliance on natural resource-based livelihoods. Impacts range from sealevel rise, inundation, and coastal erosion, to more frequent and intense tropical storms, and higher temperatures. The adverse impacts of climate change and disasters are a continuing threat to social and economic development, and future projections indicate that these impacts will get worse (Ministry of Natural Resources and Environment of Samoa, 2005, 2017).

The coastal area of Lotofaga has been classified as a Coastal Erosion Hazard Zone (CEHZ) and a Coastal Flood Hazard Zone (CFHZ). The government has made concrete recommendations to relocate village assets outside CEHZ and CFHZ when buildings require replacement, or to ensure investment within the hazard zones to prevent and mitigate damage from coastal erosion and flooding. Other recommendations include continuing to plant trees and other vegetation in coastal areas, and identifying alternative sources of sand for domestic use, since the practice of removing sand from coastal areas has contributed to coastal erosion. Furthermore, Lotofaga could be threatened by inappropriate land use practices such as deforestation, cattle farming, and agriculture. These activities have increased the rate of inland erosion and the supply of silt to the coast (MNRE, 2007).

Notably, the village does not have a comprehensive development plan. Implemented initiatives are, in general, stand-alone projects or ad hoc initiatives not connected to one another, and the majority of them are donor-oriented.

\subsection{Research design}

For this study, I developed a culturally sensitive research design that combined two worldviews and knowledge systems - Western and Samoan. While it was necessary to combine different knowledge systems, the voices of the participants were at the centre of the research design.

As discussed in this study, the extremely challenging task of disentangling climate change from other migration drivers reinforces the need to contextualise and understand migration drivers from the point of view of the people in their own social and geographical contexts. The use of a research design that combined three complementary approaches - exploratory, qualitative, and interdisciplinary opened up many new and previously under researched areas for study. The exploratory approach enabled an understanding of the multi-faceted interactions between climate change and population movements on a small scale. The qualitative approach allowed me to listen to the people's voices and to understand that the individuals' and families' holistic wellbeing is rooted in worldviews, values, beliefs, knowledge, and experiences. Mobility within this context has to be understood in a 
holistic way as it involves extended families, those living in the villages, and those who have moved to Apia and abroad. The interdisciplinary approach, grounded in Samoan worldviews, drew on both the voices of people affected by climate change and forced to move and selected insights of modern technical knowledge. Both sources of knowledge were integrated to create an interdisciplinary understanding. Although this new understanding is limited in time, and to a particular context, it was used as a lens to identify critical issues at the national level.

\subsection{Data collection}

Information for this study was collected between 2012 and 2014 in Samoa and New Zealand. Two types of research methods were considered.

First, I used Western methods, namely semi-structured interviews and a comprehensive document review to contextualise the research. Twelve key informants were interviewed in Samoa and New Zealand. Participants were selected purposively, in view of their knowledge of and expertise in climate change and population movements. Seven interviews took place in Samoa and five in Auckland. Respondents in Samoa included local leaders, government staff, and representatives from international organisations and research centres. In Auckland, respondents included representatives of New Zealand governmental and non-governmental organisations, and Samoan leaders in New Zealand. The comprehensive document review, covering a 30-year period (1985-2015), was an on-going process that included collecting published and unpublished records.

Second, the conversational Pacific method called talanoa was employed to interview people affected by climate change. Although the study was family- and village-based, it was necessary also to include the extended Lotofaga community, namely family members who have migrated to Apia and Auckland. Twenty-nine talanoa were conducted with groups and individuals. Participants were villagers and migrants living in Apia and Auckland. With talanoa it was possible to capture the essence of the holistic Samoan worldviews, intrinsically attached to ancestral lands. Using talanoa meant that conversations with the participants were more meaningful when Samoan protocols were followed and when Samoan language was used. In Lotofaga, individual and group talanoa were conducted in the Samoan language, with the support of two research assistants.

When using talanoa, an open technique can be used. In some cases, the precise nature of questions is not determined in advance. In other instances, guiding questions can be helpful. The researcher's decision will depend on the way in which the talanoa develops (Vaioleti, 2006). For the purpose of this study, I prepared a number of guiding questions and a list of topics to be covered during the talanoa with participants in Samoa and Auckland, bearing in mind that there was room for flexibility and inclusion of new issues. 


\subsection{Data analysis}

All semi-structured interviews and talanoa were audio-recorded, transcribed, and translated. After that, a thematic analysis was used as a method for identifying, analysing, and reporting patterns (themes) within the data.

Understanding the theoretical underpinnings of the research is a crucial stage before starting any thematic analysis involving Pacific data collection. As Farrelly and Nabobo-Baba (2012, p. 4) write:

If we want to understand ourparticipants' hopes and struggles, we need to holistically contextualise the words they share with us as we move with them through the course of their daily lives. But this movement is not only physical. When our participants talk, they carry us on a cognitive journey, imaginatively moving us from past to present to future so that we can better understand how they live and feel their world.

In the data analysis phase, the integrity and validity of the data was ensured through discussions with the research assistants, the village High Chief, and key informants. It was a sort of triangulation where I asked for clarification of relevant concepts, metaphors, and descriptions that allowed me to understand the profound meaning of the narratives and its nuances. I had plenty of three-way discussions aimed at ensuring that the voices of participants were heard and truly reflected in the research findings.

The same considerations were taken when analysing the semi-structured interviews with key informants. In addition, secondary data collected in parallel with the village study was used to contextualise the participants' voices.

In this study, the integration of different knowledge layers was undertaken by evaluating ways in which the collected materials were in agreement or conflict. The purpose was to discover or identify common ground concepts, theory, or assumptions through which the insights might be reconciled. The interdisciplinary approach provided a means for understanding various sources of information, while situating the village in the broader Samoan context. With this understanding and contextualization, two primary implications of the research design emerged. First, the approach validated the importance of traditional knowledge as expressed by participants in the village study. Second, the secondary information and results of the interviews with key informants reinforced the village-level study.

Interdisciplinary understanding means that eventually a new knowledge is generated, and new methods may become available to different knowledge cultures. In this study, an understanding of the environmental migration dynamics in Lotofaga has been generated. 


\section{$4 \quad$ Findings}

\subsection{Climate change understandings}

While familiar with the term, people in Lotofaga have different understandings of what climate change means for them and of how the technical information about climate change they receive can apply to their daily lives. Furthermore, the memories of disasters, such as the 2009 tsunami and the 2012 cyclone, were woven into and influenced participants' perceptions of climate change. The 2009 tsunami destroyed large stretches of the south and southeast coasts of Upolu, including villages neighbouring Lotofaga.

Although the technical underpinnings of the term 'climate change' might be unclear, participants were aware of the changes in their environment, and the effects these have had on their lives and livelihoods. A number of participants associated climate change with changes in temperature and precipitation: noting that weather patterns have become unpredictable and extreme all year round.

One interesting finding was the number of participants who framed their responses in terms of issues of climate justice and political concerns. They emphasised that climate change is caused elsewhere, and vulnerable areas like Lotofaga are disproportionately affected. A key informant said:

It's quite unfair to start talking about climate change, how you adapt to climate change or how much contribution you bave to make towards a global responsibility, when we have contributed negligibly or even nothing to the problem. (Key informant who lives in Apia)

A woman who lives in Auckland was more constructive when she said that climate change is a common responsibility:

Climate change is about all the happenings and the challenges surrounding people's lives. It needs demonstration of leadership, policies to be set at national, regional and global levels to benefit people. (Female matai in her 60s who lives in Auckland)

\subsection{Impacts of climate change and extreme weather events}

Participants showed great awareness of larger scale impacts of changes as seen in the following examples:

I know there are lots of changes nowadays... cyclones are happening more these days in our lifetime, but in the old days there was never any, or rarely any, occurrences in Samoa. (Woman villager in her 50 s)

The change of the weather is huge. Cyclones... I think when I was young I never saw anything like that... I can also see the sea level rise. If you go there, you can see the difference [between] when you were young and now. When you go back there is a big difference, like you've seen before on the coast. (Male matai in his 50s who lives in Auckland) 
In terms of climate change, because I go back frequently, and I visit Lotofaga, I see a lot more erosion... sea erosion of the beaches and the shores; there's a lot more of that. When I was young, the beach was much further into the lagoon; now it's much further inland. Our family land, as part of the lower part of Lotofaga, has been eroded gradually. (Male matai in his 60s who lives in Auckland)

Regarding changes in marine and terrestrial environments, most participants' comments about changes in the marine environment resulting from climate change and disasters focused on the decline of and changes in fish species in reefs and the lagoon, coral bleaching, sea-level rise, high waves, and changes in the currents. A number of people noted that today there are fewer fish and far fewer shellfish, and that fishing is more difficult. For instance:

These days, almost no fish. If there are any, you get small ones, not like in the past, when the fish were big. I also noted that after the tsunami our coral is bleaching rapidly. (Woman villager in her 60s)

Less was said about the impact of climate change on terrestrial ecosystems. Lotofaga's natural forests are highly vulnerable to climate change and also to unsustainable land use practices. A key informant, representing an NGO in Samoa explained these issues:

In Samoa, climate change is affecting our forests. There are forest fires as result of droughts. There's clear interference in the normal cycles of rainfall patterns. Then, the cyclones have caused serious damages in our forests. (Key informant in Samoa)

Participants also highlighted the impacts of climate change and disasters on their quality of life. All participants saw a direct link between changing weather patterns, water availability, and health and disease. Some examples:

There are lots of diseases within our country because of the changes in the weather, rapid changes... it's hot. These days, lots of diseases have arisen due to the differences in the weather. (Woman villager in her 40s)

The change of climate these days is huge. Have you seen our children's bodies? Lots are suffering from different types of diseases. Lots of diseases have arisen from the dirt, because of the change we see now. When the sun beats down hard, you burn. When it's fiercely hot, it's similar to the red-hot heat of a fire. That's how I know there are huge changes. (Woman villager in her 50s)

It was also said that high temperatures affected work and productivity:

The weather has put some people down; they feel tired; they feel sick sometimes. That's why people stay in their houses; nobody likes to go to [work] the maumaga [taro-patch] because they feel... it's like burning inside. Before you worked hard, but now only small things [make] you feel tired. (Man villager in his 50s) 
I'm tired because of the weather. It's really hot these days for me. As a consequence of the hot weather, there is an increase in diseases. Our bodies feel weak; we don't know who will do the [work] when weakness and laziness set upon us, when you can't be bothered because of the rapid changes in weather. (Woman villager in her 50s)

These reflections on the linkages between variable weather patterns and human health are in line with external documentary evidence. According to the World Health Organization (WHO) (2015), human health is already affected by both climate variability and climate change, and the overall impact for most populations is negative. The impacts are expected to grow as climate change continues, exacerbating existing threats and undermining progress in development and health.

Participants also mentioned the impacts of climate change on food security. Discussions confirmed my observations that families in Lotofaga produce a range of agricultural, livestock, and marine goods for food. Participants said that most families achieve food security through a combination of factors of food availability and accessibility, cash income (informal sales), and support from family members living in Apia and abroad. Few families face periods of food insecurity derived from the lack of labour force or low income. However, for all families, climate change and natural hazards represent a threat to food security because their primary livelihoods, such as semi-subsistence agriculture and fishing, are sensitive to climate-related impacts.

Another important finding is that climate change has differentiated effects and thus tends to exacerbate differences among groups. While most families in Lotofaga appeared to be resilient to the impacts of climate change, a group of vulnerable families is emerging because of labour shortages, poor access to remittances, and insufficient support. Families and groups with limited access to resources and support systems have fewer adaptation options, are more vulnerable to the impacts of climate change, and are less able to use mobility as an adaptive mechanism. However, I propose that these families cannot be classified as "trapped populations" (Warner et al., 2012), because the fa'a Samoa, extended families, and village support system play a major role in buffering socio-economic and environmental risks with practices of solidarity and obligations.

For most families, the injection of remittances usually helped address some basic needs and also enabled families to generate further livelihood options such as purchasing livestock, agricultural inputs, and fishing equipment. Clearly migration and, in turn, migrant remittances now play a key role in diversifying families' income generation, enabling them to meet their needs, contribute to the church, fulfil the cultural obligation of fa'alavelave (family assistance in the form of labour or goods), and adapt to climate change.

Gender-differentiated impacts resulting from gender inequalities that limit access to information and resources for women deserve further research as well as climate change impacts on youth, elders, and other vulnerable groups. 


\subsection{Traditional knowledge and community resilience}

Traditional knowledge is a major factor in families' resilience in dealing with climate change, all the while adapting to changing times and conditions. An overwhelming finding was that, as in the past, villagers, and particularly elders, draw on centuries of traditional knowledge and oral history, as a base from which they observe, monitor changes, make predictions, and act accordingly. The knowledge and practices are generated, stored, accumulated, and shared among 'aiga family members who live in the village, in urban Apia, and abroad. Elders are especially well respected for their knowledge and wisdom.

The Samoan seasonal calendar is still used as a valuable early-warning system, particularly in the case of extreme events (Lefale, 2003). Traditional knowledge associated with climate change and disasters is applied in different facets of life, such as farming, fishing practices, forestry, housing, and traditional social support systems. For instance, semi-subsistence livelihood activities have been adapted to the natural variability of the climate and other external shocks. A number of safety mechanisms established for sustainable agriculture are evident, such as the production of surpluses, crop diversification, produce storage, and control of food consumption. As in the past, these methods have enabled families to mitigate the risks and effects of climate variability and to ensure food security.

In fishing, traditional practices have been implemented, such as limiting access to certain areas, establishing no-catch zones, and enacting species-specific prohibition during certain seasons. These practices not only contribute to sustainable resource management and ecosystem protection; they also help guarantee food reserves in times of necessity. In forestry, traditional practices are still in use, and are valued not only for their part in the conservation of natural resources, but also in activities associated with cultural identity. People know the ecological, economic, and socio-cultural significance of different plants used for food, fuel, medicine, clothing, ornaments, and ceremonies (UNESCO, 2013).

Another area of knowledge found in this study relates to traditional housing. While Western-style home construction has been gradually replacing the traditional fale in Lotofaga, some families are keenly aware of the importance of preserving their traditional architectural knowledge to mitigate the impacts of climate change and extreme events. The fale is an example of a disaster-resilient house, as its open structure allows strong winds to pass straight through, and the complex system of lashing offers flexible movement and strength to confront the changing winds (Wilson, 2014).

Some elders raised concerns about the erosion of traditional knowledge among the younger generation, especially as a result of an increase in the cash economy, changes in consumption, migration, and the lack of recognition of traditional knowledge in formal education (Fa'asau, 2011). In their view, these influences have made village youth less resilient. This finding is consistent with other research that indicates that erosion of traditional knowledge and skills may increase vulnerability 
and risk for younger generations (Nakashima, Galloway McLean, Thulstrup, Ramos Castillo, \& Rubis, 2012).

\subsection{Climate change adaptation}

One of the main findings of this research is that although climate change and extreme weather events affect people's lives, families in Lotofaga demonstrate great strength and resilience in ameliorating the impacts of climate-related events. Over generations, families have adopted different strategies to respond to climate variability and disasters. Today, they are using a mix of traditional and Western modern technical knowledge, drawing on their family and village social support systems, using their customary land tenure entitlements, and using population movements to enhance their adaptive capacity.

There is evidence that families' traditional knowledge, values, and beliefs continue to guide their interactions with their land, sea, and natural resources and that their responses to climate change are framed around the fa' $a$ Samoa.

Participants showed great pride, as seen in the following comment:

We have learnt to adapt for generations. People in Samoa can actually survive so well with very limited resources because that's their nature, that's how they live. This may be limited in the concept of how Westerners see it but it's rich. There are rich resources in the rivers, in the sea, in the land, and the people have lived very happily. And a lot of the practices they have actually adapted to, [like] issues of climate change, when they conserve their mangroves, when they harvest their marine resources or even harvest agricultural produce and some of their crops. Actually, crops are a measure of adaptation. (Key informant in Samoa)

Today, families not only rely on their traditional knowledge to adapt to climate change, but also have some access to modern technical information, mainly from climate change adaptation projects and disaster risk reduction initiatives.

Moreover, in order to respond to the impacts of climate change and disasters, families rely on their village organisations such as the fono o matai, the women's komiti (women's committees), and the churches because they can contribute to disseminating information on climate change and disaster preparedness among villagers and, most importantly, they can help in aid coordination.

In our community, there's a whole range [of organisations] and we have our men, our fono, and a women's group, like the committee and even the church. The women have their own group and the younger generation also belp, the boys who are not the chiefs yet. (Male matai in his 70 s who lives in Lotofaga)

The endurance of the customary land tenure system provides the platform for families' responses to the impacts of climate change and disasters. Whilst the use of this resource - customary land - is feasible in Lotofaga, it would likely be differ- 
ent in other contexts. In any case, the importance of customary land as a buffer against climate change cannot be underestimated.

With regard to remittances, even if migrants do not directly experience the impacts of climate change, they support extended families after disasters, and in times of water scarcity, drought, and other events associated with climate change. Participants in Apia provide immediate support, which is easier considering that the village is not far from the capital. In the case of family members living in Auckland, participants send remittances, organise fundraising events, and even travel back to Lotofaga to help in the reconstruction of houses and village infrastructure, and to contribute to the recovery of crops and plantations.

Although families in Lotofaga have relied on remittances to recover from the effects of climate change and disasters, the costs of adaptation to climate in the village and the costs of migration may increase financial pressure on migrants already settled in both Apia and New Zealand. Therefore, the reliance on remittances to finance climate change adaptation initiatives in the village might be uncertain in the future.

\subsection{Human mobility as an adaptation strategy}

Another major finding of this research is that climate-related factors have become prominent in discussions about mobility. While economic, social, and cultural drivers, such as the desire for more land for cash cropping or the benefits of education and employment associated with moving to Apia or overseas are undeniably the priority concern, climate change impacts are factored in and have a place in family decision-making.

Identifying and defining different types of human mobility associated with climate change is not an easy task because there are several overlapping concepts, terms, and categories (Ferris, 2015). The findings of this study are in agreement with Hugo (1996), who proposed that mobility in the context of climate change must be examined along a continuum, ranging from totally voluntary migration to totally forced migration. Very few decisions are entirely forced or voluntary, as seen in the case of Lotofaga. Mobility has not occurred in the extremes, but along a continuum, and it has been linked to the extent of slow- and rapid-onset events related to climate change.

The Lotofaga village study showed that mobility is not a new phenomenon; people have always moved internally and abroad (Macpherson \& Macpherson, 2009). However, population movements now play an integral part of people's adaptation strategies to climate change, as seen in cases of displacement and relocation from coastal areas to inland customary lands or temporary and permanent migration to Apia. Further, overseas migration is becoming more prominent. Families might be engaged in all or some of these types of movement at any point in time. The circular movement is present within each of the patterns of mobility a coming and going both actual and in the mind. 
In the case of Lotofaga, the movements inland have responded not only to improvements in infrastructure and expansion of agriculture, but also to climaterelated factors - slow- and sudden-onset events - which have influenced people's decisions to move inland to their customary lands. Some participants said they had moved voluntarily to higher ground after assessing the risks associated with living in the coastal areas. Other participants said they had been temporarily displaced and had sought refuge on higher ground within their customary lands.

One participant explained the process of relocation inland with these words:

A lot of new inland roads have been built in the country. And this is something that is necessary in terms of reacting to what is happening on the coastline. The most dangerous things, and the most concerning for us, are sea-level rise and natural disasters. Many villages have been actually moving where the road has been placed and people move inland where the road is. (Woman participant in her 50s who lives in Apia)

Two participants, who are now living in Apia, reflected on how sea-level rise had been a consideration in their own family patterns of movement:

Our family have land [in the coastal area], and my great-grandparents used to live on the beach before they moved [inland]. They moved even when my father was young, and he is about 60 plus now. It was a sort of relocation inland. If you've been to Lotofaga you can see that the sea has moved inland a bit more. It's slowly coming in. I remember when I was younger we used to have a wider beach from where our land is, but now our land is bere and the sea is right about there [showing how the beach has shrunk]. So, I think it's been affected by climate change. We don't have any sea walls or anything to prevent the erosion of the sand, so in the next ten years it will be very different. We'll keep moving inland. (Woman in her 40s who lives in Apia)

There have been internal movements, maybe because of climate change. Thirty, forty years ago, Lotofaga had a beautiful beach, a long, wide, sandy beach. It used to be the most beautiful village. As I'm recalling the olden days, ten, fifteen years ago, maybe more, the malae [central gathering place of the village] was close to the beach, close to the High Chief's residencies. It was a nice village. Climate change can be a reason for movements, with strong waves and high tides that hit the village. The village is different now; no more houses in the coastal area; people have moved inland. (Man in his 60s who lives in Apia)

In a similar vein, a male participant who lives in Auckland noted:

When we go back to the 1940s and 1950s, part of our family was mostly down in the lower part of the village. Then they moved up to high land. Now they are safe. The beach was much wider, out into the lagoon. Now it seems it's gone. You can tell that the sea has moved inland; it's much closer now than it was before. Man in his 60s who lives in Auckland) 
Voluntary relocation is likely to continue in the future, and this is mainly associated with climate-related problems. A common view is that population movements inland are inevitable because they are triggered by climate change and disasters.

In the case of Lotofaga, the relocation inland cannot be considered 'planned relocation'. Instead, I see this as a voluntary process that has also been induced by public policies. Even though families have voluntarily decided to move inland, a process that started at least three decades ago, the government has also been encouraging relocation to higher grounds. For instance, the Coastal Infrastructure Management Plan (CIM Plan) for Lotofaga identified coastal erosion and flash flooding along the river as the main factors that have pushed families to relocate inland. The CIM Plan recommended continuing to relocate houses beyond the coastal area (MNRE, 2007).

Regarding migration to urban areas, the main finding was that although climate change and disasters were not yet considered to be a significant driver of migration to the capital Apia, the externalities of climate change might become push factors for both temporary and permanent movements. Families' livelihoods have been affected by cyclones, flash floods, high rainfall, high temperatures, and dry periods. The effects on agriculture, for instance, are linked to the loss of quality and quantity of production. Moreover, unstable and inconsistent food production caused by climate variability has affected farmers' capacity for self-sufficiency and also their capacity to generate income from their crops.

An issue that has emerged from the study is the migration of young people to Apia. In Samoa, youngsters are increasingly abandoning agriculture and rural areas in search of better livelihoods in urban areas. Findings suggest that climate change and disasters will increasingly become push factors in the move to the capital in search of protection, food, and shelter. The extent of any climatic event will determine the duration and the type of migration.

A young male villager referred to the challenges of agricultural adaptation to climate change. He said that he was forced to move to Apia when food security became an issue:

I work in Apia for short periods of time. Farming is not very good now [in Lotofaga], so [there's] not enough food. The plan, so far, is for me to live back here [in Lotofaga], and go to Apia for work and then come back. (Male villager in his 30s)

Other participants associated the move to Apia with fear and also a loss of land as a result of slow- and sudden-onset events:

Sea-level rise and coastal erosion are affecting us. Families cannot cultivate their crops because of these problems. That's why people want to live in Apia. (Woman villager in her 60s)

There are lots of families that have gone to Apia. They've gone to look for land to live on in Apia because they are very frightened about staying here. As time passes, and if it [an 
extreme event7 suddenly happens again they would be extremely frightened. So, they've all gone away. (Woman villager in her 40s)

Although the majority of the Auckland-based participants said climate change had not been their main reason for migrating overseas, they agreed that this is an issue that is starting to be considered as a cause of migration. A female participant living in Apia noted some links between climate change and overseas migration:

People have migrated overseas, mainly to New Zealand and Australia. It might not be to do with climate change but it's a lot to do with economics. But economics rests on the environment and natural resources. And if people find that their natural resources are not supplying them adequately for the church needs and for their cultural needs, and for family needs, that might be one reason why they move. (Woman in her 50s who lives in Apia)

Interestingly, some participants saw a closer association between migration and the effects of disasters as seen in these comments:

What worries us are the disasters... some people have gone to New Zealand with their children; they've gone because they no longer want to stay in Samoa. (Woman villager in ber 20s)

Some people are lucky with the [New Zealand migration] quotas; they can go to New Zealand... Some people say that it's hard to work on plantations; they don't get any money from that. And then disasters hit the country, so people decide to have a new life. Some [people] move to New Zealand to make a better living. (Woman villager in her 30s)

As seen in the previous comments, climate change and disasters are increasingly being considered in discussions about migration abroad. However, in the short term, migration overseas is, and will continue to be, conditioned by different natural and financial barriers as well as immigration regulations, quotas, and other factors that set limits on the number of people entering a country. If migration opportunities arise, it is likely that there will be significant increases in out-migration. Presently, people who can cross borders may be relatively well off, compared with those who do not have the means to move overseas, especially young people (individuals and families) for whom migration overseas is an option.

Although a number of people may want to move to Apia or overseas, others want to stay in Lotofaga, particularly the elders. A common sentiment among elder participants was their desire to stay in their village and country, regardless of climate-associated problems. They said that they are prepared for future changes, adding that they have been adapting to environmental changes for generations.

Clearly, it is difficult for people of Lotofaga, especially the elderly, to imagine leaving or abandoning their family lands because of climate change. Participants associated their land with culture, identity, and traditions (see also Farbotko, this volume). The sense of belonging is so strong that it embraces the extended Lotofaga community, those who live in the village and those widespread communities 
in Apia and abroad. For all of them, the village represents home. Responses here were so strongly put that they are listed in full:

Climate change? No. We will never go away from Lotofaga for that reason. We never think about it; we never have a second thought whatsoever about moving away. We were born and raised in Lotofaga. So why should we leave if we have a beautiful place? We are so lucky. We love each other; we help each other; that is what [it is] all about. That is what the fa'a Samoa is all about, respecting one another. That's right from the top, from the matai of the 'aiga to the younger generation, to the youngest person of our family; we help each other. (Male matai in his 70 s who lives in Lotofaga)

Nothing [referring to climate change and disasters], even the tsunami, the cyclones that came two or three times, changed our minds to run away to Apia or abroad. The only reason why our people went abroad is to help their families, and to create whatever they want. (Woman villager in ber 60s)

Cyclones bit the country and even worse events. There was a tsunami in Samoa but you've seen Lotofaga now. We have a bit of higher land away from the sea, where we can evacuate [to]. We'll go and settle there. Because of the tsunami we lost our house, and my dad's house. But that doesn't make us leave, because I am Samoan; it [the land] is so precious to me. (Woman in her 60s who lives in Apia)

As mentioned previously, migration prospects appeared to be more uncertain for the youth. They need viable prospects, such as work opportunities, to remain in the village, otherwise, migration to Apia or abroad is considered one of the best options. Apart from the economic benefits, migration overseas entails a social and cultural element of prestige, and it can be linked with the desire of many men to acquire matai titles; the money earned overseas may contribute to acquiring a title in Samoa.

Interestingly and overarching all, Lotofaga people stressed very compellingly that no matter how far they go or for how long, their village is their home, their place of identity and belonging. This finding aligns with Lilomaiava-Doktor's (2009) use of the Samoan concept of malaga (short-term movements or circular mobility) to explain people's và or relationship with the land. Connectedness to land is so strong that migration does not signal a severance of ties or being uprooted but "in the eyes of those involved," migration is a continual "going back and forth". People's mobility has a profound impact on the extended family ("aiga) as a whole because mobility is not only an individual affair but also a family effort.

\section{$5 \quad$ Conclusions}

As in the rest of the country, climate change in Lotofaga is increasingly seen as an urgent issue affecting all aspects of people's lives from families' livelihood security through to health, traditional knowledge, social structures, and culture. Further- 
more, sudden-onset events, such as cyclones, storm surges, and floods, and slowonset events associated with climate change, such as sea-level rise, affect terrestrial and marine ecosystems, infrastructure, and water supply.

Lotofaga participants highlighted responses to climate change as largely familybased, as opposed to individual, and also the extreme resilience of families. For instance, participants emphasised their capacity to anticipate climatic events, absorb external changes and stresses, and recover from the effects of climate change and disasters without compromising their long-term prospects. It is clear that resilience in Lotofaga cannot be seen as a fixed end state, but rather as a dynamic set of conditions and processes.

Furthermore, this group of families, far from regarding the impacts of climate change in a fatalistic way, has continuously sought solutions aimed at adapting to changing environmental conditions. Moreover, they have applied holistic solutions to increase their family and community resilience to a wide range of challenges. In times of distress, people prioritise not only their own safety and needs, but also their 'aiga's and the village's wellbeing.

Lotofaga families use a mix of at least four strategies to develop resilience to climate change. First, people engage in internally driven responses by using their traditional knowledge and combining it with modern technical information. Second, they draw on and nurture strong family and village social support systems. Third, they utilise their customary land tenure entitlements. Fourth, they use population movements. Notably, not all the families had access to all of these strategies; therefore, vulnerability factors need to be further researched.

Regarding environmental migration, climate change and disasters are drivers of population movements in Lotofaga as in the rest of the coastal villages in Samoa, and this trend is likely to continue in the medium and longer term. Indeed, research findings indicate that climate-related impacts are affecting and will continue to affect mobility in different ways. Even though I have used conventional typologies to explain climate-induced mobility - i.e. displacement, relocation, and migration to urban areas and abroad - I have taken into account the cultural underpinnings of these movements. In Lotofaga, mobility has usually been induced by a wide variety of drivers, amongst which climate-related factors now play an increasingly important role. Even so, factors cannot be isolated from their socioeconomic and cultural context. Climate-induced mobility must be studied in an interdisciplinary way and, as the findings confirm, environmental migration cannot be considered as a separate category of mobility. In view of the projected increase of slow- and sudden-onset events associated with climate change, it is anticipated that the number of people induced or forced to move will rise. Among the urgent issues that must be addressed at the policy level are the relocation of at-risk families, the need for adaptation to the effects of climate change in situ, the need to provide support to those who migrate, and the legal challenges around people displaced by climate-related threats. Furthermore, both scientific technical information and traditional knowledge have to inform and influence policy design and 
practices. Two implications for policy design have been identified in this study. First, the voices of people affected by climate change must be incorporated in both research and policy. Not only are they the ones affected by changes, but also their knowledge and aspirations have a central place in understanding and addressing climate change challenges. Second, climate-induced mobility must be studied within specific social and cultural contexts (place and time) so that tailored interventions can be put in place. In sum, the design of any climate change adaptation initiative must be conducted in consultation with communities to ensure that their priorities are considered.

\section{Acknowledgements}

This chapter is based on my doctoral thesis, Samoa: Exploring the linkages between climate change and population movements, Auckland University of Technology, New Zealand, 2016. I would like to thank the people of Lotofaga, those living in the village, Apia and Auckland, and particularly to the Honourable Fiame Naomi Mata'afa, the village High Chief and Deputy Prime Minister of Samoa. Also, I wish to express my deep gratitude to my thesis supervisors Professor Tagaloatele Peggy Fairbairn-Dunlop and Doctor Fa'alāva'au Juliet Boon Nanai.

\section{Bibliography}

Anae, M., Coxon, E., Mara, D., Wendt-Samu, T., \& Finau, C. (2001). Pasifika education research guidelines. Ministry of Education of New Zealand. Retrieved from https://www.educationcounts.govt.nz.

Barnett, J., \& O’Neill, S. (2010). Maladaptation. Global Environmental Change, 20(2), 211-213.

Barnett, J., \& O’Neill, S. (2012). Islands, resettlement and adaptation. Nature Climate Change, 2(1), 8-10.

Battiste, M. (2000). Introduction: Unfolding the lessons of colonization. In M. Battiste (Ed.), Reclaiming indigenous voice and vision (pp. 1-2). Vancouver, Canada: University of British Columbia Press.

Bedford, R., \& Hugo, G. (2012). Population movement in the Pacific: A perspective on future prospects: Department of Labour, Ministry of Business Innovation and Employment of New Zealand. Retrieved from http://www.mbie.govt.nz.

Burson, B. (2010). Protecting the rights of people displaced by climate change: Global issues and regional perspectives. In B. Burson (Ed.), Climate change and migration. South Pacific perspectives (pp. 159-180). Wellington, New Zealand: Victoria University.

Campbell, J. (2010). Climate change and population movement in Pacific Island countries. In B. Burson (Ed.), Climate change and migration. South Pacific perspectives (pp. 29-50). Wellington, New Zealand: Victoria University. 
Campbell, J., \& Bedford, R. (2014). Migration and climate change in Oceania. In E. Piguet \& F. Laczko (Eds.), People on the move in a changing climate (Vol. 2, pp. 177-204).

Chilisa, B. (2012). Indigenous research methodologies. Thousand Oaks, CA: Sage Publications.

Connell, J. (2011). Small island states and islands: Economies, ecosystems, change and migration. UK Government Office for Science. Retrieved from https://webarchive.nationalarchives.gov.uk/20121206061212/http://www.bis .gov.uk/assets/foresight/docs/migration/drivers/11-1186-dr16-drivers-ofmigration-in-islands.pdf.

Dun, O., \& Gemenne, F. (2008). Defining 'environmental migration'. Forced Migration Review, 31, 10-11. Retrieved from http://www.fmreview.org.

Fa'asau, H. (2011). The protection of Samoa's traditional knowledge and expressions of culture. Measina a Samoa. University of Samoa, 5, 71-95.

Fairbairn-Dunlop, P. (1991). E Au Le Inailau a Tamaitai: Women, education and development, Western Samoa (Unpublished doctoral thesis, Macquarie University).

Fairbairn-Dunlop, P. (2000). Changing perception of land: Samoa. Proceedings of the 2000 National Environment Forum. Ministry of Natural Resources and Environment 2. Retrieved from http://www1.mnre.gov.ws.

Farrelly, T., \& Nabobo-Baba, U. (2012, December). Talanoa as empatbic research. Paper presented at the Meeting of the International Development Conference, Auckland, New Zealand.

Ferris, E. (2015, July). Climate change, migration and the incredibly complicated task of influencing policy. Keynote address at the Conference on Human migration and the environment: Futures, politics, invention. Durham University, Durham, UK. Retrieved from https://cmsny.org/wp-content/uploads/FERRIS-1JULY-2015.pdf.

Flores-Palacios, X. (2016). Samoa: Exploring the linkages between climate change and population movements (Doctoral thesis, Auckland University of Technology).

Gegeo, D. W., \& Watson-Gegeo, K. A. (2001). "How we know": Kwara'ae rural villagers doing indigenous epistemology. The Contemporary Pacific, 13(1), 55-88.

Government of Samoa. (2014). Samoa's smooth transition strategy report. Retrieved from https://www.un.org/en/development/desa/policy/cdp/ldc_documents /2015-cdp-samoa-transition.pdf.

Hugo, G. (1996). Environmental concerns and international migration. International migration review, 30(1), 105-131.

Hugo, G. (2008). Migration, development and environment: IOM. Retrieved from https://publications.iom.int/system/files/pdf/mrs_35.pdf.

International Organization for Migration. (2016). Migration and climate change. Retrieved from https://www.iom.int/migration-and-climate-change. 
Laczko, F., \& Piguet, E. (2014). Regional perspectives on migration, the environment and climate change. In E. Piguet \& F. Laczko (Eds.), People on the move in a changing climate. The regional impact of environmental change on migration (pp. 1-20). Cham: Springer.

Lay, G., Tamua, E., Murrow, T., \& Meleisea, M. (2000). Samoa. Auckland, New Zealand: Pasifika Press.

Lefale, P. (2003). Seasons in Samoa. Water and atmosphere, 11(2), 10-11. Retrieved from https://www.niwa.co.nz.

Lilomaiava-Doktor, S. I. (2009). Beyond "migration": Samoan population movement (malaga) and the geography of social space (va). Contemporary Pacific, $21(1), 1-32$.

Macpherson, C., \& Macpherson, L. (2009). The warm winds of change: Globalisation and contemporary Samoa. Auckland, New Zealand: Auckland University Press.

McNamara, K. E., \& Gibson, C. (2009). 'We do not want to leave our land': Pacific ambassadors at the United Nations resist the category of 'climate refugees'. Geoforum, 40(3), 475-483.

Meleisea, M. (1987). The making of modern Samoa: Traditional authority and colonial administration in the history of Western Samoa. Suva, Fiji: Institute of Pacific Studies of the University of the South Pacific.

Ministry of Natural Resources and Environment of Samoa (MNRE). (2005). Samoa. National adaptation programme of action (NAPA). Retrieved from https:// unfccc.int/resource/docs/napa/sam01.pdf.

Ministry of Natural Resources and Environment of Samoa (MNRE). (2007). Coastal infrastructure management plan. Lotofaga District. Plan development. Retrieved May 18, 2015 from http://www.mnre.gov.ws.

Ministry of Natural Resources and Environment of Samoa (MNRE). (2017). The national environment sector plan. Retrieved from https://www.mnre.gov.ws/mnreredesign/wp-content/uploads/2017/08/NESP-2017-2021.pdf.

Nabobo-Baba, U. (2008). Decolonising framings in Pacific research: Indigenous Fijian Vanua research framework as an organic response. Alternative: An International Journal of Indigenous Peoples, 4(2), 140-154.

Nakashima, D. J., Galloway McLean, K., Thulstrup, H. D., Ramos Castillo, A., \& Rubis, J. T. (2012). Weathering uncertainty: Traditional knowledge for climate change assessment and adaptation: UNESCO-UNU. Retrieved from http://www.ipmpcc.org.

Paton, K., \& Fairbaim-Dunlop, P. (2010). Listening to local voices: Tuvaluans respond to climate change. Local Environment, 15(7), 687-698.

Samoa Bureau of Statistics. (2011). Population and housing census 2011. Retrieved from http://www.sbs.gov.ws.

Samoa Bureau of Statistics. (2016). Samoa socio-economic atlas. Retrieved from http://www.sbs.gov.ws.

Smith, L. T. (1999). Decolonizing methodologies: Research and indigenous people. Dunedin, New Zealand: University of Otago. 
Stephenson, J., Newman, K., \& Mayhew, S. (2010). Population dynamics and climate change: What are the links? Public Health, 32(2), 150-156.

Thaman, K. H. (2007, December). Re-thinking and re-searching Pacific education: Further observations. Keynote address presented at the meeting of the NZARE Conference, Christchurch, New Zealand.

United Nations Educational, Scientific and Cultural Organization \& International Information and Networking Centre for Intangible Cultural Heritage in the Asia-Pacific Region. (2013). Traditional knowledge for adapting to climate change. Safeguarding intangible cultural heritage in the Pacific. Retrieved from http:/ / unesdoc.unesco.org/images/0022/002253/225313E.pdf.

United Nations University, Institute for Environment and Human Security, \& United Nations Economic and Social Commission for Asia and the Pacific. (2015). Climate change and migration in the Pacific: Links, attitudes, and future scenarios in Nauru, Tuvalu, and Kiribati. Retrieved from http://i.unu.edu /media/ehs.unu.edu/news/11747/RZ_Pacific_EHS_ESCAP_151201.pdf.

Va'a, U. F. (2007). The fa'amatai in transition in a mission village. In A. So'o (Ed.), Changes in the matai system (pp. 185-206). Apia, Samoa: Centre for Samoan Studies, National University of Samoa.

Vaioleti, T. (2006). Talanoa research methodology: A developing position on Pacific research. Waikato Journal of Education, 12, 21-34. Retrieved from http:/ / researchcommons.waikato.ac.nz.

Warner, K., Afifi, T., Henry, K., Rawe, T., Smith, C., \& de Sherbinin, A. (2012). Where the rain falls: Climate change, food and livelihood security, and migration. CARE France and UNU-EHS. Retrieved from http:/ / wheretherainfalls.org.

Wilson, C. (2014, October 2). Samoa's architects look to the past to boost climate resilience. Thomson Reuters Foundation News. Retrieved from http://news.trust.org/.

World Health Organization. (2015). Human bealth and climate change in Pacific island countries. Retrieved from https://iris.wpro.who.int/bitstream/handle/10665.1/ 12399/9789290617303_eng.pdf. 